\title{
Unusual presentation of early lymphogranuloma venereum in an HIV-1 infected patient: effective treatment with $1 \mathrm{~g}$ azithromycin
}

\author{
R F Nieuwenhuis, J M Ossewaarde, W I van der Meijden, H A M Neumann
}

Sex Transm Infect 2003;79:453-455

\begin{abstract}
The incidence of lymphogranuloma venereum (LGV) is low in the western world. Early LGV is characterised by bubonic disease following a painless papule or small ulcer. We report a white bisexual male who presented with a painful perianal ulcer, inguinal lymphadenitis, and concomitant infection with human immunodeficiency virus 1 (HIV-1). Chlamydia trachomatis serovar L2 was identified as the cause after polymerase chain reaction and genotyping the major outer membrane protein by restricted fragment length polymorphism. Treatment with a single dose of $1 \mathrm{~g}$ azithromycin was effective. This case illustrates that early LGV may mimic other genital ulcer diseases, such as genital herpes or chancroid, especially in HIV infected patients. In the western world, LGV must still be included in the differential diagnosis of bubonic disease with or without sexually acquired ulcers.
\end{abstract}

L ymphogranuloma venereum (LGV) is a sexually transmitted disease (STD) endemic to parts of Africa, South -East Asia, South America, and some Caribbean islands. In the western world, the incidence is low and most cases are considered to be imports. ${ }^{1}$ Early stages of LGV are characterised by a marked bubonic disease in the groin after a painless papule or a shallow ulcer. Late manifestations include strictures and fistulas when the rectum is involved, and disfiguring conditions of the external genitalia, such as elephantiasis and esthiomene. ${ }^{2}$ We report a patient with a painful perianal ulcer, inguinal lymphadenitis, and a concomitant infection with human immunodeficiency virus 1 (HIV-1).

A 39 year old, bisexual white man initially presented at our STD clinic with a painful perianal ulcer, bilateral swollen lymph nodes in the groin, and general malaise. Three weeks before the onset of the symptoms he had had unprotected, receptive anal intercourse with a white man in Amsterdam. Unfortunately, partner notification was not possible because of the anonymous nature of the sexual contact in a "gay" sauna. The public health department in Amsterdam was notified about our patient, but no cases of LGV had been reported in Amsterdam in the previous 6 months. Our patient denied any overseas travel, and this sexual contact was the only sexual encounter in the previous 6 months. The patient had a history of recurrent herpes labialis and an appendectomy, but no known history of STDs. He was not taking systemic medication and denied injecting drug use. Direct diagnostic tests (dark field microscopy, Tzanck smear, and rapid plasma reagin) revealed no abnormalities. Clinical suspicion of primary genital herpes prompted us to treat with valaciclovir.

Two weeks later he presented with severe complaints. Physical examination showed a slightly febrile man with a marked swelling in the right groin. The swelling was firm, fluctuant, and slightly tender. The perianal ulcer had clearly increased in size (diameter $2.5 \mathrm{~cm}$ ). The bottom of the fairly deep ulcer was red and showed some purulent exudate (fig 1). Remarkable features were the irregular ulcer rim and the severe pain. A clinical diagnosis of chancroid was therefore strongly suspected and he was accordingly treated with a single dose of $1 \mathrm{~g}$ azithromycin orally. ${ }^{3}$

Treponemal serology was positive in the TPPA and fluorescent treponemal antibody test (FTA-abs) tests, but negative in the Veneral Disease Research Laboratory (VDRL) test. Histopathological examination of an incisional biopsy from the ulcer showed a dense granulating infiltrate and atypical patterns of ulceration, but no spirochaetes were observed by immunofluorescence. No infective agents could be identified in the periodic acid-Schiff, Grocott, and Giemsa staining. A blood stained purulent aspirate was obtained from the bubo in the right groin as shown in figure 2 . Haemophilus ducreyi was absent in Gram stained smears and cultures of both the aspirate and ulcer swab. $H$ ducreyi, Treponema pallidum, and herpes simplex virus were not identified in the ulcer swab using the multiplex polymerase chain reaction (M-PCR) technique. ${ }^{4}$ However, Chlamydia trachomatis infection was demonstrated in urine and rectal specimens by PCR. C trachomatis serology showed relatively high levels of IgA and IgG antibodies (5.2 and >5.3 ratio to cut-off value, respectively; Savyon SeroCT peptide enzyme immunoassay), suggestive of invasive infection. Genotyping of the gene encoding the major outer membrane protein (MOMP) using nested PCR and restriction fragment length polymorphism (RFLP) ${ }^{5}$ identified $C$ trachomatis serovar L2 in both the urine and rectal specimen (fig 3), confirming the diagnosis of LGV. ${ }^{67}$ The LGV responded well to treatment with azithromycin during the next 2 weeks.

Furthermore, the HIV serology (HIV-1) was positive with a viral load (HIV-RNA) of higher than $1.0 \times 10^{5} \mathrm{U}$. The CD4+ and CD8+ T lymphocyte counts were $0.27 \times 10^{9} / 1$ and $0.71 \times 10^{9} / 1$, respectively. Chest $x$ ray was normal and the cerebrospinal fluid showed no signs of neurosyphilis. However, on the basis of treponemal antibodies in the serum, 2 weeks after receiving the azithromycin he was additionally treated for late latent syphilis with three injections of $2.4 \mathrm{mU}$ benzathine benzyl penicillin intramuscularly at weekly intervals.

Lymphogranuloma venereum is caused by $C$ trachomatis serovars L1, L2, and L3. It causes invasive infection with preference for the regional lymph nodes. In the majority of cases, patients seek medical assistance because of buboes. ${ }^{1}$ The primary lesion, usually a small and painless papule or ulcer, may escape attention. Only $25-33 \%$ of the patients report a history of such lesions. ${ }^{8}$ Documentation on LGV and concomitant HIV infection is limited. It was suggested that HIV infection does not influence the clinical presentation of 


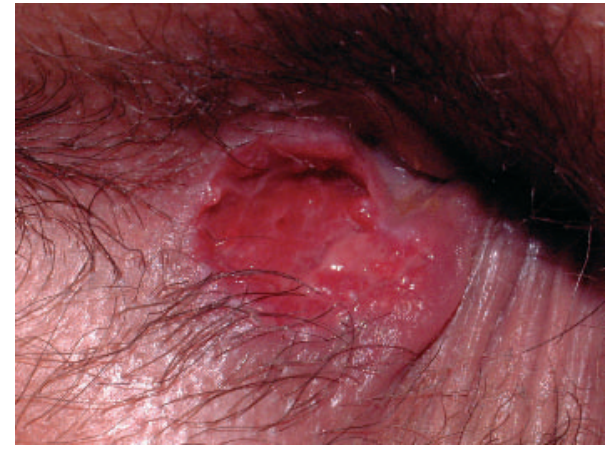

Figure 1 Painful perianal ulcer with irregular ulcer rim.

LGV. ${ }^{9}$ However, Rompalo et al ${ }^{10}$ reported that HIV infected patients (mean CD4+ count: $0.66 \times 10^{9} / 1$ ) with genital ulcer disease (GUD) are more likely to present with deeper, larger, and multiple lesions. The patient reported here had a low CD4+ count $\left(0.27 \times 10^{9} / 1\right)$ and presented with a large and painful perianal ulcer mimicking severe genital herpes or chancroid. The final diagnosis of LGV was based on the presence of $C$ trachomatis serovar L2 in combination with the negative VDRL test, immunofluorescence, and Giemsa staining. Moreover, detection of $H$ ducreyi was negative in M-PCR

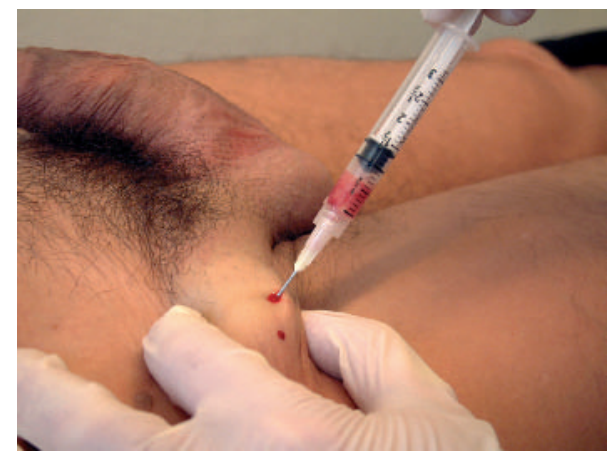

Figure 2 Fine needle aspiration from the bubo in the right groin.

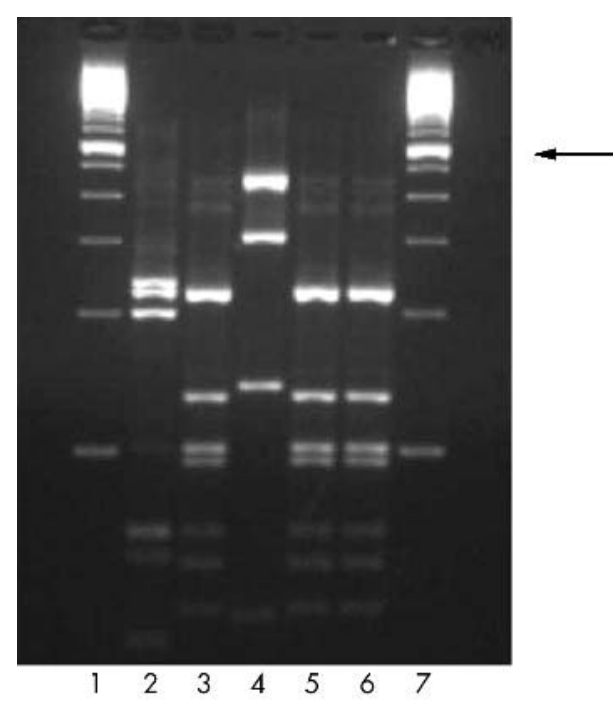

Figure 3 PCR based RFLP genotyping. Lanes 1 and 7 show a 100 bp ladder (arrow indicates the thick 600 bp band). Lanes $2-4$ show laboratory reference strains L1, L2, and L3, respectively. Lane 5 and 6 show the urine and rectal specimen of the patient.

\section{Key messages}

- Although very rare, this case proves that lymphogranuloma venereum (LGV) still exists in the West, and therefore western physicians must remain vigilant for local outbreaks of LGV.

- In HIV infected patients, the presentation of LGV may be unusual mimicking genital ulcer diseases such as chancroid and genital herpes.

- The presented case suggests that a single dose of $1 \mathrm{~g}$ azithromycin is possibly effective in treating early LGV.

from the ulcer swab, and in cultures from both bubo pus and the ulcer. However, these diagnostic techniques are less than $100 \%$ sensitive. ${ }^{11}{ }^{12}$

According to the current European STD guidelines, the recommended treatment of early LGV is $100 \mathrm{mg}$ doxycycline twice daily for 21 days. ${ }^{3}$ Uncomplicated chlamydial infections with non-LGV strains are effectively treated with a single oral dose of $1 \mathrm{~g}$ azithromycin. ${ }^{13}$ Clinical evidence is lacking on its use in LGV. ${ }^{14}$ Our patient responded well to a single dose of $\mathrm{l} \mathrm{g}$ azithromycin, demonstrating its possible effectiveness in early LGV. Treatment recommendations in HIV infected patients are the same, although it is presumed that the time to heal may be prolonged in these patients. ${ }^{15}$ Recently, Moodley et al ${ }^{16}$ reported that HIV-l coinfection was not associated with a decreased response to treatment. The findings in our patient support their observations.

We conclude that in the western world LGV must still be included in the differential diagnosis of bubonic disease with or without sexually acquired ulcers, even when the patient denies sexual contact with partners from endemic regions. Physicians in the West must also remain vigilant for the possibility of local outbreaks of LGV as a result of ever increasing travel to and from the endemic areas.

\section{ACKNOWLEDGEMENTS}

We thank Dr B Tank, Department of Dermatology and Venereology, for correcting the English; Mr J van der Stek, Department of Dermatology and Venereology, for preparing the clinical pictures; and Mrs H F M Willemse, Department of Medical Microbiology and Infectious Diseases, is acknowledged for performing the necessary laboratory work.

\section{CONTRIBUTORS}

RFN was responsible for clinically managing the patient, reviewed the literature, and wrote the manuscript; JMO was responsible for the laboratory diagnosis, advised on microbiological aspects of managing the patient, and reviewed and revised the manuscript; WIvdM supervised the management of the patient and reviewed and revised the manuscript; HAMN is Head of the Department of Dermatology and Venereology and critically commented on the manuscript.

\section{Authors' affiliations}

R F Nieuwenhuis, W I van der Meijden, H A M Neumann, Department of Dermatology and Venereology, Erasmus MC, Dr Molewaterplein 40, 3015 GD Rotterdam, Netherlands

J M Ossewaarde, Department of Medical Microbiology and Infectious Diseases, Erasmus MC, Dr Molewaterplein 40, 3015 GD Rotterdam, Netherlands

Correspondence to: Dr W I van der Meijden, Department of Dermatology and Venereology, Postbus 2040, 3015 GD Rotterdam, Netherlands; w.i.vandermeijden@erasmusmc.nl

Accepted for publication 21 July 2003 


\section{REFERENCES}

1 Perine PL, Stamm WE. Lymphogranuloma venereum. In: Holmes KK, Mardh PA, Sparling PF, et al, eds. Sexually transmitted diseases. New York: McGraw-Hill, 1999:423-32.

2 Mabey D, Peeling RW. Lymphogranuloma venereum. Sex Transm Infect 2002;78:90-2.

3 Roest RW, van der Meijden WI. European guideline for the management of tropical genito-ulcerative diseases. Int J STD AIDS 2001;12(Suppl 3):S78-83.

4 Bruisten SM, Cairo I, Fennema H, et al. Diagnosing genital ulcer disease in a clinic for sexually transmitted diseases in Amsterdam, The Netherlands. J Clin Microbiol 2001;39:601-5.

5 Ossewaarde JM, Rieffe M, van Doornum GJ, et al. Detection of amplified Chlamydia trachomatis DNA using a microtiter plate-based enzyme immunoassay. Eur J Clin Microbiol Infect Dis 1994;13:732-40.

6 Bauwens JE, Orlander H, Gomez MP, et al. Epidemic lymphogranuloma venereum during epidemics of crack cocaine use and HIV infection in the Bahamas. Sex Transm Dis 2002;29:253-9.

7 Kellock DJ, Barlow R, Suvarna SK, et al. Lymphogranuloma venereum: biopsy, serology, and molecular biology. Genitourin Med 1997;73: 399-401.
8 Rothenberg RB. Lymphogranuloma venereum. In: Freedberg IM, Eisen AZ, Wolff $\mathrm{K}$, et al, eds. Fitzpatrick's dermatology in general medicine. New York: McGraw-Hill, 1999:2591-4.

9 Scieux C, Barnes R, Bianchi A, et al. Lymphogranuloma venereum: 27 cases in Paris. J Infect Dis 1989;160:662-8.

10 Rompalo AM, Lawlor J, Seaman P, et al. Modification of syphilitic genital ulcer manifestations by coexistant HIV infection. Sex Transm Dis 2001;28:448-54.

11 Morse SA, Trees DL, Htun Y, et al. Comparison of clinical diagnosis and standard laboratory and molecular methods for the diagnosis of genital ulcer disease in Lesotho: association with human immunodeficiency virus infection. J Infect Dis 1997; 175:583-9.

12 Lewis DA. Diagnostic tests for chancroid. Sex Transm Infect 2000;76:137-41.

13 Stary A. European guideline for the management of chlamydial infection. Int J STD AIDS 2001;12(suppl 1):S30-3.

14 Clinical Effectiveness Group. National guideline for the management of lymphogranuloma venereum. Sex Transm Infect 1999;75(Suppl 1):S40-2

15 Czelusta A, Yen-Moore A, van der Straten M, et al. An overview of sexually transmitted diseases. Part III. Sexually transmitted diseases in HIV-infected patients. J Am Acad Dermatol 2000:43:409-32.

16 Moodley P, Sturm P D, Vanmali T, et al. Association between HIV-1 infection, the etiology of genital ulcer disease, and response to syndromic management. Sex Transm Dis 2003;30:241-5.

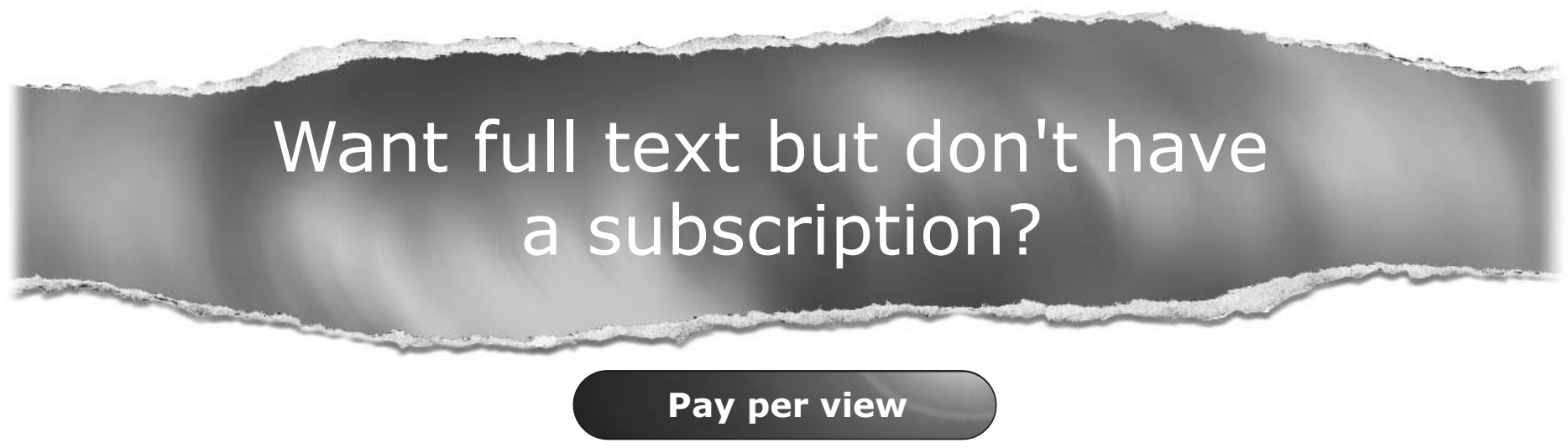

For just US\$8 you can purchase the full text of individual articles using our secure online ordering service. You will have access to the full text of the relevant article for 48 hours during which time you may download and print the pdf file fo personal use.

\section{www.stijournal.com}

